JCP 16(1) Goncalves 12/17/01 8:26 AM Page 1

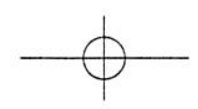

Journal of Cognitive Psychotherapy: An International Quarterly, Vol. 16, No. 1, 2002

\title{
From Reactive to Proactive Dreaming: A Cognitive-Narrative Dream Manual
}

\author{
Óscar F. Gonçalves \\ João G. Barbosa \\ University of Minho, Portugal
}

\begin{abstract}
Most traditional approaches to dream work in psychotherapy have conceptualized dreams as reactive narratives of individual's waking life. The objective of this paper is to show how a cognitive narrative approach can contribute to the use of dreams as proactive constructions for waking life. The paper begins with a discussion of the role of dream work in the history of psychotherapy as well as its role in the birth and development of cognitive therapy. Constructivist approaches to cognitive therapy, as illustrated by cognitive-narrative psychotherapy, are presented as an alternative way for the use of dream work in psychotherapy. The paper concludes with a description of how the cognitive-narrative approach to dream work can be used in psychotherapy.
\end{abstract}

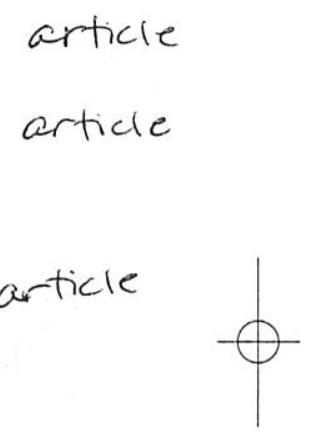

$\mathrm{T}$

he ancient Greco-Egyptian deity Serapis was the God of Dreams. Serapis lived in a temple, the Serapeum, where people could go to have dreams induced. Particularly in the Greco-Roman traditions, this primitive form of dream work was associated with healing and fertility. Since those early times, dreams have been linked to the idea of revelation, cure, and spiritual healing. Thus, it should come as no surprise that the earliest formulations of psychotherapy $\mathrm{t}^{\text {the }}-\frac{-1}{\mathrm{~m}}$ "scientific" spiritual healing of the century ${ }^{\text {Wwere }}$ closely connected with 20 th $/ \frac{-1}{m}$ dream work and the interpretation of dreams.

The birth date of psychotherapy is often identified with Sigmund Freud's publication of his seminal work, The Interpretation of Dreams (Freud, 1900/1966). It is in this work that Freud, using the dream as "royal road" to knowledge of the unconscious, offers a theory of mind that constitutes the central theoretical foundation of psychoanalysis. Freud believed, at that time, that dreams were essentially safety valves for unconscious wishes and that through dreams the person was fulfilling primitive desires. The central task of the psychoanalyst was one of helping the analysand decode the analogical and metaphorical language of dreams by means of psychoanalytic interpretation. Interestingly, dreams continued to be regarded as revealing messages, this time not from Gods but from within the person. It is interesting to note that/ since Freud, most of the psychodynamic approaches that have 
been developed tend to use dreams as the "royal road" for the understanding of psychological functioning. Such was indeed the case with the formulations of Jung (1974) and Adler (1936).

Other therapeutic approaches, such as Gestalt (Perls, 1969) and Experiential therapies (Gendlin, 1969), offered alternative theories of dreams and specific strategies for dream work. Contrary to the psychodynamic therapists, dreams in these approaches were used not as a way of decoding the hidden language of the unconscious but rather as a way of expanding the clients' experience.

In a manner similar to Freud, the early formulations of cognitive therapy came from the studies of dream. In 1959, while Aaron T. Beck was practicing psychoanalysis, he received his first research grant to study dreams (Weishaar, 1993). Beck's research on dreams was instrumental for his early formulations of a cognitive approach to depression. This involved identifying the roots of depressive ideation (Beck \& Ward, 1961). From this research program, Beck developed the idea that dreams are highly correlated with the themes of waking life and that both could represent important tools for the study of psychopathology. As Rosner (1997) has recently described, Beck moved dream work from the latent to the manifest level of analysis and from a motivational to a cognitive view. Later, other cognitively oriented therapies have followed up on this idea with suggestions to use dreams as thematic expressions of the patient's cognitions and not as symbolic expressions to be intrepreted or decoded (Freeman, 1991; Freeman \& Boyll, 1992; Freeman \& White, this issue).

In sum, dream work has been closely connected with the evolution of the psychotherapeutic movement. In the psychodynamic tradition, dreams were seen as symbolic expressions of the unconscious, and the task for the therapist was to decode them through psychoanalytic interpretation. In the experiential tradition, dream work was seen as a way of uncovering and expressing emotions and thus enriching clients' life experience. Finally, early cognitive therapist suggested that the introduction of dreams offered important expressions of clients' ideational mechanisms that could be used to uncover certain thematic thoughts and also as tools for cognitive restructuring. That is, dreams could be changed in the very same way that we change thought processes. For all these approaches, dream work has been conceptualized as a reactive process in which a dream is used to reveal some unconscious, cognitive, and emotional processes. In what follows we will be describing a cognitive-narrative approach in which dream work is presented as an essentially proactive process in which the therapeutic dyad uses dreams as a way of expanding the client's personal narrative.

\section{A COGNITIVE-NARRATIVE APPROACH TO DREAM WORK}

In her cognitive experiential approach to dream work in psychotherapy, Clara Hill (1996) states that the language of dreaming makes use of two essentially human characteristics: our tendencies to use metaphors and to be inveterate story tellers. In fact, metaphors are the central way of condensing meaning, and the abundant 
JCP 16(1) Goncalves 12/17/01 8:26 AM Page 3

metaphors in dreams can be understood as part of the ongoing construction of meaning (see Gonçalves \& Craine, 1990). Additionally, we make meaning out of organizing this experience in terms of narrative (Gonçalves, 1994a, 1995). Hill concludes that, given this reliance on narrative and metaphorical processes, dreams are ways of making sense of what happens to us in waking life, thereby allowing the assimilation of experience. In sum, what Clara Hill seems to be suggesting is that the narratives found in dreams are not different from the narrative patterns of waking life. During dreams, as in waking life, individuals are in a constant process of assimilating the variety and multiplicity of their experiences through the organization of their personal metaphors and narratives.

Seligman and Yellen (1987) developed a curious proposal that pre-dated Hill's understanding. They based their formulation on Molinari and Foulkes' (1969) research showing that the REM (Rapid Eye Movements) stage of sleep is composed of two subphases: periodic bursts of REM alternating with REM quiescence. Apparently, during the bursts, the individual is overwhelmed by visual and sensory stimulation while in the quiescent period the individual describes more of an intellectual meaning-like experience. The authors suggest, based on this research, that dreams come from the individual's attempt to integrate in a coherent narrative plot the multiplicity and mostly random nature of sensory and emotional stimuli. Seligman and Yellen positioned their proposal within the framework of the improvisationist theory of dreaming as formulated by Hobson and McCarley (1977), stating that "there is internally generated sensory information from the pontine brain stem which periodically rises up into the forebrain where it is integrated with higher perceptual, conceptual, and emotional information" (Seligman \& Yellen, 1987, p. 5).

In sum, both Hill's and Seligman and Yellen's theories attribute to the dreamer the role of a storyteller that attempts to construct a coherent narrative out of the bursts of sensory and emotional stimulation experienced during both awake and dream stages. Like any improvisationist, the dreamer is a narrator attempting to bring a coherent plot of meaning out of the diversity of experience. This metaphor of the individual as a narrator brings us to the constructivist and narrative formulations of cognitive therapy (Gonçalves, 1997a, 1997b).

Rosner (1997) has suggested that constructivist psychology has the potential to be "stronger and more comprehensive" in providing theoretical and clinical foundations for understanding dreams clinically. Rosner bases this statement on the idea that:

Constructivist, and particularly narrative and developmental constructivists $7 .$. , are further interested in understanding and manipulating those nonconscious, core-organizing principles and processes through which individuals make meaning. The narrativists, for example, view the inherent need to create a coherent narrative through which to understand and integrate experience. (p. 263)

According to the cognitive-narrative perspective, human beings actively construct their knowledge by organizing their experience in terms of narratives. The narrative constitutes a way of introducing some kind of order in face of the cahotic nature of experience (Gonçalves, Korman, \& Angus, 2000). Research on the use of narrative in psychotherapy tends to show that different narrative modes seem to be associated 
with distinct therapeutic results, with good outcome being associated with increasing levels of coherence, internality, and reflexivity (Angus \& Hardtke, 1994; Pennebaker, 1993). This was found to be true for both waking and dream narratives (Luborsky, Barber, \& Diguer, 1992).

Cognitive narrative psychotherapy is a therapeutic methodology aimed at helping the client to come up with a multiplicity of narrative contents, to explore the variety of narrative modes (a progressive direction from more external to more internal and reflexive), and to be able to come up with alternative ways of construing coherence out of their narratives (Gonçalves, 1995b, 1998). The therapeutic process encompasses five phases:

$\left.\mathrm{f}_{1}\right)_{\gamma}$ recalling narratives; (NCI)

$(2)_{\wedge}$ objectifying narratives;

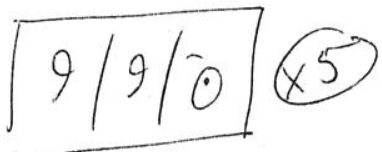

(3) subjectifying narratives;

4) metaphorizing narratives; and

$(5)_{\mu}$ projecting narratives. $\mathrm{N}-3$

\section{ケ}

In the first stage, recalling narratives, clients develop a recalling attitude, learning how to use past and daily experiences as important tools for meaning-making. The second phase, objectifying narratives, helps clients expand the sensory dimensions of their narratives (e.g., visual, auditory, olfactory, gustatory, kinesthetic). The third stage consists of subjectifying narratives. In this stage, clients are helped in exploring the multiplicity of emotions and thoughts that can be constructed for each narrative. Meaning-making is the central objective of the fourth phase of the therapeutic process and involves metaphorizing narratives. Metaphors are seen as ideal meaning-making symbols that are isomorphic with the content of the narrative. The objective is therefore to help clients to develop multiple meanings out of every narrative. The final stage $\hat{\lambda}$ projecting narratives ${ }^{2}$ aims to help clients in the development of alternative, meaningful metaphors and testing these meanings through the projection of the new narratives. The final objective is to direct the client into forthcoming life narratives, bringing with it a sense of acting and authorship.

Cognitive-narrative psychotherapy makes three central assumptions about dreams (see Gonçalves, Korman, \& Angus, 2000, for a more detailed presentation):

\footnotetext{
(1) During the dream state (not unlike the waking state), the individual experi-

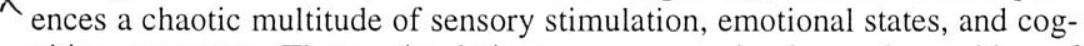
nitive processes. These stimulations emerge randomly as the residue of wakening life experience.

In the face of this continuous stimulation, the individual faces the task of organizing this random and chaotic experience into a coherent meaningful process.

33) Finally, the construction of coherence implies the need to actively impose a $\lambda$ narrative order.
}

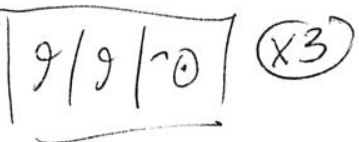

Based on these three assumptions, we have derived an application of cognitive narrative therapy to dream work in order to: 
1. expand the complexity of the dreamer's sensorial, emotional, and cognitive experience;

2. allow for the possibility of the emergence of a more coherent and meaningful dream narrative; and

3. provide room for the proactive induction of more complex, coherent and diverse dreams.

In the following section we will present a cognitive-narrative manual for dream work, illustrating each phase of the dream work process.

\section{THE COGNITIVE-NARRATIVE USE OF DREAMS:}

\section{A MANUAL}

The following manual is intended to be used to facilitate dream work in psychotherapy. The central objective of the manual is to help the client use the dream in order to:

(1) recall the dream for use in the therapeutic session;

(2) increase the level of dream experience by the narrative elaboration of different sensory dimensions;

23) increase the level of dream experience by the narrative elaboration of differ$\checkmark$ ent emotional dimensions;

$9_{44}$ increase the level of dream experience by the narrative elaboration of differ$\wedge$ ent cognitive dimensions;

(5) derive multiple meanings from the dream experience; and

(6) proactively construct alternative dreams and enhance these dreams in wak-

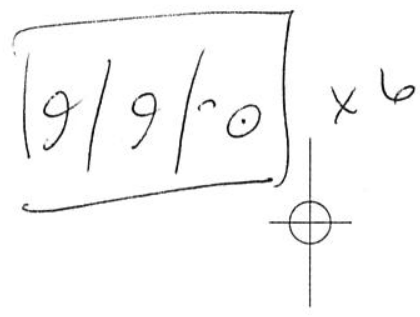

In order to accomplish these objectives, the client and therapist deal with the dream along the six phases of cognitive narrative psychotherapy: recalling? objectifying 9 of emotionally subjectifying: cognitive subjectifying

\section{Introducing the Dream Work}

Objective. The process begins by having the therapist present the therapeutic objectives of the dream work. In the first stage, the client is told that the objective of the dream work is to increase the level and complexity of dream experience; better understand the dream; make connections between the dream and other issues of wakening life; and proactively create alternative dreams. At this stage the therapist informs the client about the methodology to be used.

Method. The following sequence is suggested:

1) Present in simple language the objectives of dream work (e.g., "The objec-

$\Lambda$ tive of our work today is to expand the experience and understanding of your dream, to connect the dream with wakening life, to rehears, and experience alternative dreams").

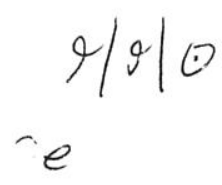


(2) Describe the therapeutic sequence (e.g., "We'll begin by recalling the differ$\Lambda_{\text {ent }}$ parts of the dream; then we'll be exploring in detail the sensory, emotional, and cognitive experiences of the dream; next we'll move into constructing some meanings out of the dream; finally we'll explore alternative dream").

\section{Stage One-Recalling the Dream}

Objective. The recall phase has as it's most central objective to allow the client to piece together the dream fragments in order to pursue further clinical work.

Method. This phase follows a three stage sequence:

(19) The therapist prompts the client to elaborate on the dream narrative in a $\boldsymbol{\gamma}$ coherent way. The therapists asks open questions such as: "Please tell me about what happened? Where did it all took place? Where were you? Who was there? How did it all begin? What did you think? What did you do? What did all the others do? How did it all end?"

(2) The client is asked to identify different sections or "chapters" in his/her dream narrative (e.g., "Can you identify or divide your dream in different parts?")

33) Finally, the client is invited to select any part of the dream that he/she wants

$\wedge$ to pursue further (e.g., "Which part or parts of your dream would you like to pursue further?").

\section{Stage Two ¿-Objectifying the Dream}

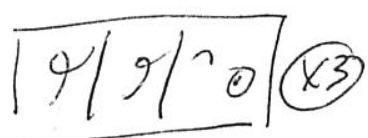

$9|9|-0$

3)

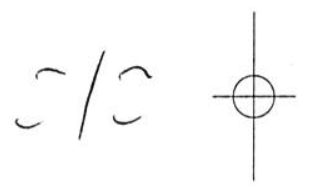

Objective. The objective of this phase is to increase the level of experience by having the client elaborate on the different sensory dimensions of the dream. Here the client is invited to explore the sights, sounds, smells, tastes, and physical sensations present in the dream.

Method. The following sequence is suggested:

$g_{1}{ }_{1}$ Ask open-ended questions about the visual dimensions of the dream (e.g.,

1 "What are you seeing as you describe this dream? Tell me about the scenario, the different colors, shades, etc.").

12) Ask open-ended questions about the auditory dimensions of the dream (e.g., " "As you describe the episode, which different sounds are you noticing?").

$\sqrt{3})^{2}$ Ask open-ended questions about the olfactory dimensions of the dream (e.g., "Tell me now about any smells that you recollect from this experience").

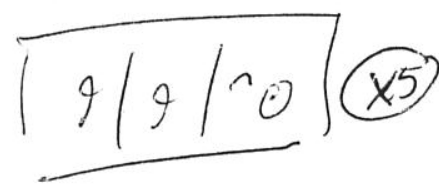

(4) Ask open-ended questions about the taste dimensions of the experience (e.g., " "What different tastes can you identify in this dream?").

55) Finally, ask open-ended questions about the physical sensations experienced $i$ in the dream (e.g., "What are you experiencing in your body as we recall this dream?"). 


\section{Stage Three -Emotionally Subjectifying the Dream $\sim / \sim$}

Objective. The attention of the therapeutic dyad now moves to the internal and emotional side of the experience. This involves an effort to increase the level of dream experience by elaborating on its emotional dimensions.

Method. The client is instructed to go through the different dream scenes and explore the emotions associated with dream using a three step process:

(1) emotional activation (e.g., "What are you experiencing physically?")

22) emotional focusing (e.g., "I would like you to please exaggerate the physical

$43{ }^{3}$ experience")

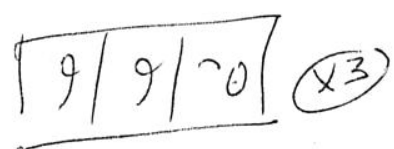
the physical experience")

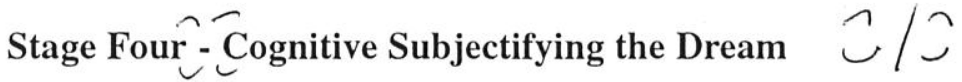

Objective. Following the emotional subjectifying, the client is invited to keep increasing the complexity of the dream experience. This is done by turning the focus of therapeutic work to the narrative elaboration of the different thoughts and cognitions associated with the experience.

Method. The client is instructed to go through the following sequence:

I19. Identify any specific thought associated with the experience (e.g., "Tell me

$\wedge$ now about all the thoughts that come to your mind which are associated with

those feelings").

(2) Have clients free-associate on those thoughts (e.g., "Try to find the thought " that is associated with the first one").

\section{Stage Fivê-iMetaphorizing the Dream $\smile / \hat{C}$}

Objective. The metaphorizing phase is the part of dream work where the client is invited to explore the different meanings associated with the dream and the link between these meanings and other thoughts in waking life.

Method. In order to accomplish this objective the following process is suggested:

(1) Invite clients to come up with a "title" (i.e., metaphor) that, in their view, ide-

ally encapsulates the central meaning of the dream (e.g., "In the same way as directors and writers choose titles to summarize the core meaning of their work, I would invite you now to come up with a title that metaphorically condenses the meaning of the episode that we have been going through").

I2f Once clients have selected a title, the therapist should help elaborate on the

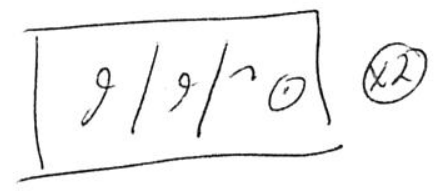

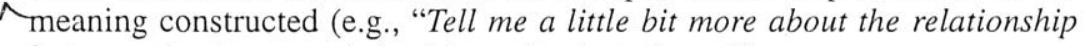
between the dream and the title you've just chosen"). 
$(3)^{9}$ The therapist should encourage clients to construct a range of meanings,

$\wedge$ exploring the episode from others' perspectives (e.g., "I'm now inviting you to assume a different point of view, a different perspective. It could be from a different character in your episode or it could be from any significant outside observer. What different titles would these people come up with?").

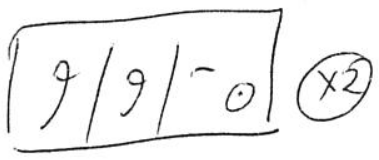

$\left.\gamma_{4}\right)^{4}$ The clients are asked again to identify connections between the dream and

$\wedge$ themes in their waking life (e.g., "What connections can you make between this dream and your waking life?").

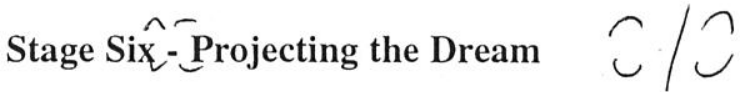

Objective. The projecting phase tries to help the client develop a dream that he/she would like to see enhanced as an alternative to the original dream.

Method. In order to pursue this goal, the client is invited to follow this sequence:

(1) To come up with an alternative metaphoric title to the dream to be projected e.g., "What would be a possible alternative dream? "What title might encapsulate the central meaning of the dream? Please tell me about the general narrative of the dream");

22. To identify the different thoughts associated with the dream (e.g., "What thoughts can you identify?");

(3) To identify the different emotions associated with the dream (e.g., "What emo^ tions can you identify?");

$(4)^{5}$ To identify the different sensations associated with the dream (e.g., "What do you see, smell, hear, taste, feel physically?");

(5) To determine the implications of this dream in waking life (e.g., "What are the implications of this dream in your waking life?");

(6) To determine what he/she could do to project the alternative dream in waking

${ }^{h}$ life (e.g., "What could you do to enhance this dream in your awakening life?").

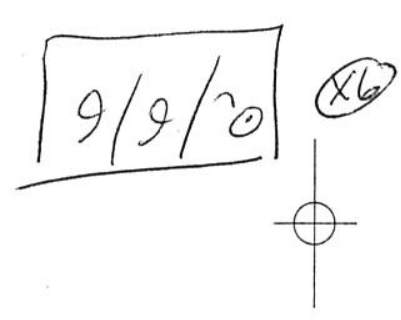

\section{CONCLUSION}

One-third of our life passes while we are sleeping. A significant part of this sleep is occupied by dreaming. Dreaming is a feature of both our biological and psychological condition by which we make sense of what goes on in our life during sleepTherefore, ignoring dreams is to neglect a significant part of our life.

As Hobson (1988) has suggested, during REM sleep there is an interplay between two complementary processes:

\footnotetext{
11. the brain stem activates brain functioning by generating a cahotic process of $\wedge$ stimulation; and

(2) the forebrain tries its best to bring a synthetic sense of coherence to this stim$\wedge$ ulation by introducing a narrative order.
}

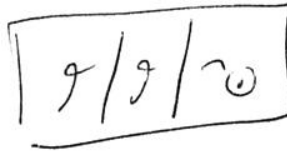


The process is not at all different from what takes place in waking, with the single difference that most of the sensory input and motor output is blockade.

The task of the dreamer is to experience the diversity of sensorial, emotional, and cognitive experiences while simultaneously struggling to integrate them into a coherent narrative and plot. The absence of waking contextual constraints allows the possibility for an unlimited creativity (e.g., hallucination qualities; intense emotionality). Also, the lack of some fundamental external constraints creates obstacles for the dreamer as he attempts to come up with a coherent narrative (e.g., distortions of time, place, and persons; delusional qualities).

The cognitive-narrative approach to dream work tries to build on the strengths and overcome the weaknesses of the dream experience by:

?19. building on the dreamer's creativity by expanding the level of sensorial, $\hat{~ e m o t i o n a l, ~ a n d ~ c o g n i t i v e ~ e x p e r i e n c i n g ; ~ a n d ~}$

25. helping the dreamer construct meaningful possibilities of coherence for the

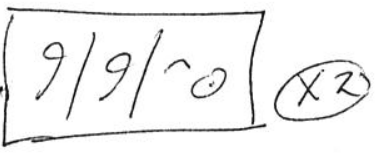

This way, rather than proposing a retroactive and interpretative approach to dream work, we suggest a proactive methodology to enhance the qualities of both dreaming and waking experience. As Hobson (1988) aptly reminded us:

All subjective experience, including dreaming, tends to be organized by the linguistic faculty of our brain-minds as a narrative scenario. And we are so intensely involved and in such peculiar ways $\hat{\kappa}^{\circ}$ in these story-films that we tend to adopt an interpretative literary stance when reacting to our dreams. But just as literature and film $\nwarrow$ regardless of their content may be profitably regarded as particular forms of expression, so may dreams also be profitably viewed as particular forms of mental experience.". (pp. 203-

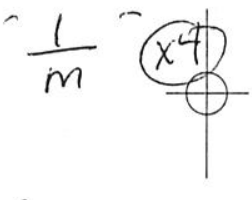
204)

\section{REFERENCES}

Adler, A. (1936) On the interpretation of dreams. International Journal of Individual Psychology, 2, 3-16.

Angus, L. E., \& Hardtke, K. (1994). Narrative processes in psychotherapy. Canadian Psychology, 35, 190-203.

Beck, A. T., \& Ward, C. H. (1961). Dreams of depressed patients: Characteristic themes in manifest content. Archives of General Psychiatry, 5, 462-467.

Freeman, A. (1981). Dreams and images in cognitive therapy. In G. Emery, S. D. Hollan, \& R. C. Bedrosian (Eds.), New directions in cognitive therapy (pp. 224-238). New York: Guilford.

Freeman, A., \& Boyll, S. (1992). The use of dreams and the dream metaphor in cognitivebehavior therapy. Psychotherapy in Private Practice, 4, 173-192.

Freud, S. (1966). The interpretation of dreams. New York: Avon. (Original work published 1900).

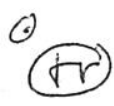

Gendlin, E. (1986). Let your body interpret your dream. Wilmette, IL: Chiron. 
Gonçalves, O. F. (1994). From epistemological truth to existential meaning in cognitive narrative psychotherapy. Journal of Constructivist Psychology, 7, 107-118.

Gonçalves, O. F. (1995a). Hermeneutics, constructivism, and the cognitive-behavioral therapies: From the object to the project. In R. A. Neimeyer \& M. J. Mahoney (Eds.), Constructivism in psychotherapy (pp. 195-230). Washington, DC: APA Press.

Gonçalves, O. F. (1995b). Cognitive narrative psychotherapy. In M. J. Mahoney (Ed.), Cognitive and constructive psychotherapies (pp. 139-162). New York: Pergamon.

Gonçalves, O. F. (1997a). Postmodern cognitive psychotherapy: From the university to the multiversity. Journal of Cognitive Psychotherapy, 11, 105-112.

Gonçalves, O. F. (1997b). Constructivism and the deconstruction of clinical practice. In T. L. Sexton \& B. L. Griffin (Eds.), Constructivist thinking in counseling practice, research and training (pp. xi-xvii). New York: TC Press.

Gonçalves, O. F. (1998). Psicoterapia cognitiva narrativa: Um manual de psicoterapia breve (Cognitive narrative psychotherapy: A brief therapy manual). S. Paulo, Brazil: Edipsy.

Gonçalves, O. F., \& Craine, M. H. (1990). The use of metaphors in cognitive therapy. Journal of Cognitive Psychotherapy, 4, 135-149.

Gonçalves, O. F., Korman, Y., \& Angus, L. (2000). Constructing psychopathology from a cognitive narrative perspective. In R. A. Neimeyer \& J. D. Raskin (Eds.), Constructions of disorder (pp. 265-284). Washington, DC: APA Press.

Hill, C. E. (1996). Working with dreams in psychotherapy. New York: Guilford.

Hobson, J. A. (1988). The dreaming brain. New York: Basic Books.

Hobson, J. A., \& McCarley, R. W. (1977). The brain as a dream state generator: An activation-synthesis hypothesis of the dream process. American Journal of Psychiatry, 134, $1335-1348$.

Jung, C. G. (1974). Dreams. Princetonf NJ: Princeton University Press.

Luborsky, L., Barber, J. P., \& Diguer, L. (1992). The meaning of narratives told during psychotherapy: The fruits of a new observational unit. Psychotherapy Research, 2, 277-290.

Molinari S., \& Foulkes, D. (1969). Tonic and phasic events during sleep: Psychological correlates and implications. Perceptual and Motor Skills, 29, 343-368.

Pennebaker, J. W. (1993). Putting stress into words: Health, linguistic, and therapeutic implications. Behaviour Research \& Therapy, 31, 539-548.

Perls, F. (1969). Gestalt therapy verbatim. New York: Bantam Books.

Rosner, R. I. (1997). Cognitive therapy, constructivism, and dreams: A critical review. Journal of Constructivist Psychology, 10, 249-273.

Seligman, M. E., \& Yellen, A. (1987). What is a dream? Behaviour Research and Therapy, $25,1-24$.

Weishaar, M. E. (1993). Aaron T. Beck. London: Sage.

Offprints. Requests for offprints should be directed to Óscar F. Gonçalves, Departamento de Psicologia, Universidade do Minho, 4700 Braga, Portugal. 